\title{
FUTURE JOINT WARFARE ANALYSIS MODEL DESIGNS
}

William G. Lese, Jr.

Deputy Director (Theater Assessments and Planning)

Office of the Director (Program Analysis and Evaluation)

1800 Defense Pentagon

Washington, DC 20301-1800, U.S.A.
Jim Metzger

\author{
Director, JWARS Office \\ Office of the Director (Program Analysis and Evaluation) \\ 1800 Defense Pentagon \\ Washington, DC 20301-1800, U.S.A.
}

\begin{abstract}
The Joint Warfare System (JWARS) is a state-of-the-art simulation of joint warfare for analysis to be developed as one component of the Joint Analytic Model Improvement Program recently approved by the Deputy Secretary of Defense. This paper describes the rationale, objective, management, approach, and status of JWARS.
\end{abstract}

\section{RATIONALE}

Existing models and simulations (M\&S) employed for analysis by the Department of Defense (DoD) are limited in their representations of joint operations and consequently limited in their ability to address current issues. Figure 1 shows recent analytic applications of theater-level M\&S. In the area of planning and programming, studies included those assisting in determining the size of the Base Force and the Bottom Up Review (BUR) Force, the Mobility Requirement Study Bottom Up Review Update (MRS BURU) study, the Nimble Dancer seminar war game, and the family of Joint Warfare Capability Assessments (JWCAs). Modernization assessments included the Joint Advanced Strike Technology (JAST) study and the Heavy Bomber / B-2 Study. Operational assessments supported Operation Desert Storm, Vigilant Warrior (the operation associated with the threatened Iraqi attack in October 1994), Commander-in-Chief (CINC) force allocation, and alternatives for dealing the situation in Bosnia. Figure 1 also shows current model limitations. Areas are color coded regarding adequacy of representation: $\mathrm{G}=$ green for good, $\mathrm{Y}=\mathrm{yellow}$ for fair, and $\mathrm{R}=$ red for poor.

In May 1995, the Deputy Secretary of Defense (DepSecDef) approved the Joint Analytic Model Improvement Program (JAMIP) to improve the ability of the DoD to address joint operations. The four phases of JAMIP are displayed in Figure 2. JWARS makes up the second and third phases and is the topic of this paper. The second ("mid term") phase is the design and development of JWARS. The third ("long term") phase is incorporation of JWARS into the "city architecture" proposed by the Director, Defense Research and Engineering (DDR\&E) and supported by the High Level Architecture (HLA) being defined under the leadership of the Defense Modeling and Simulation Office (DMSO). That "city architecture", illustrated in Figure 3 , involves the development by DMSO of a common technical framework that provides services to $M \& S$ in diverse areas--production and logistics (P\&L), test and evaluation (T\&E), analysis, and research and development (R\&D)--and the development of $M \& S$ that adhere to HLA precepts and can thereby avail themselves of those services and, as appropriate, operate in conjunction with one another.

\section{OBJECTIVE}

The objective of JWARS is to develop a state-of-the-art simulation of joint warfare for analysis. Applications will include: development of war plans and evaluation of courses of action, analyses of force structure alternatives, analyses of force structure alternatives. mission area analyses, JWCAs, determination of requirements for new warfighting capabilities, analyses of weapon system alternatives (in particular, cost and operational effectiveness analyses), and evaluation of alternatives for program and budget reviews.

\section{MANAGEMENT}

The management structure for JAMIP, including JWARS, is shown in Figure 4. The JAMIP executive committee provides overall guidance and ensures proper funding. Control of JWARS is exercised by the JAMIP steering committee, which adheres to the guidance of the 

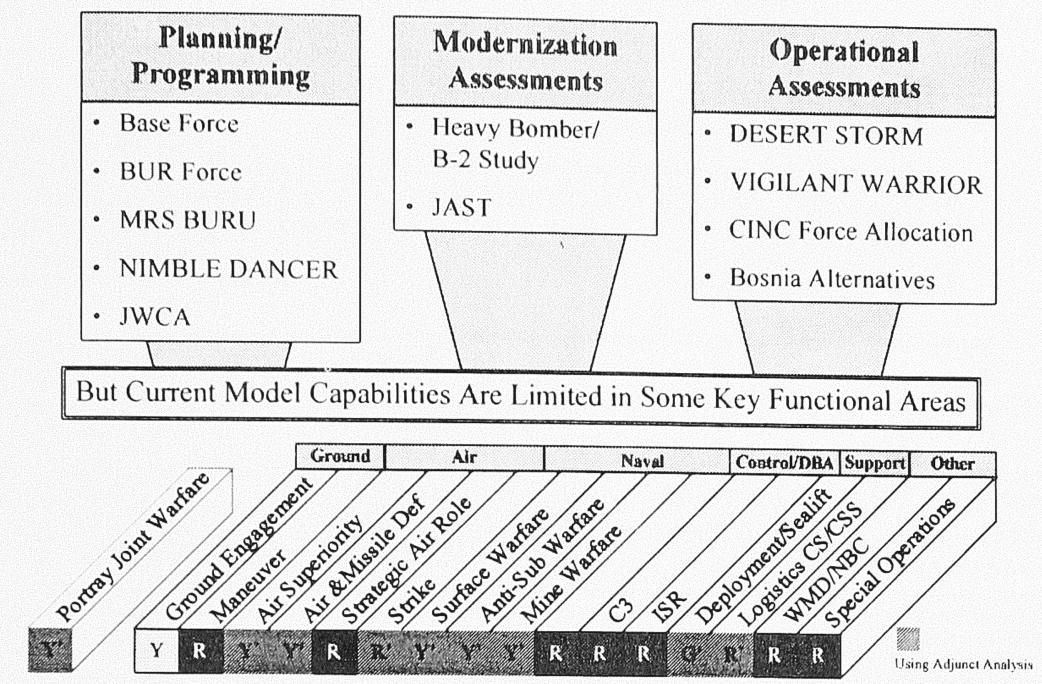

Figure 1: Analytic Applications and Current Limitations

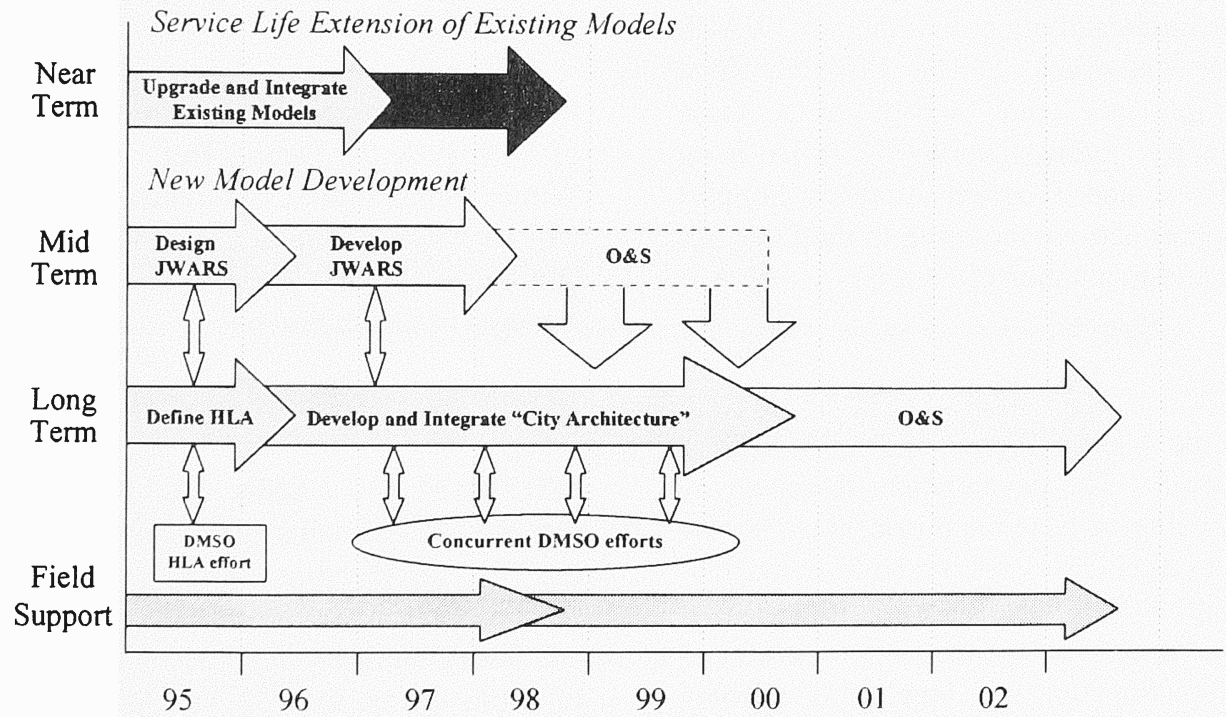

Figure 2: JAMIP Phases
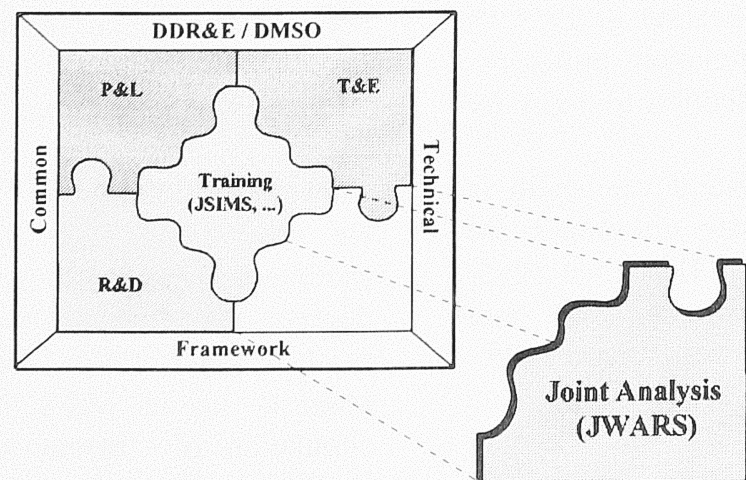

Figure 3: City Architecture 


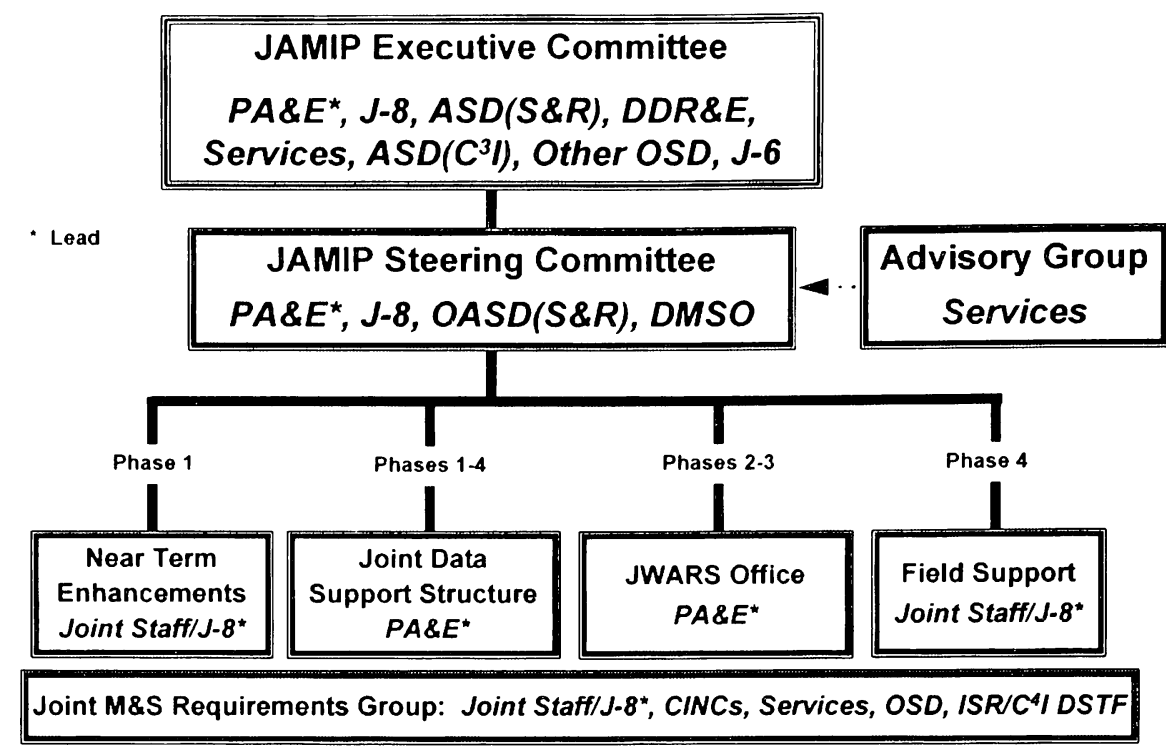

Figure 4: JWARS Management

the executive committee and allocates funds to JWARS (and other JAMIP activities). The JWARS office implements the guidance and control from these committees. Organizationally, the JWARS office is an element of the Plans and Program Analysis Support Center, a DoD support activity reporting to the Director, Program Analysis and Evaluation (DPA\&E)

\section{APPROACH}

The approach to be taken in developing JWARS is illustrated in Figure 5. The development is driven by user requirements being collected and prioritized by the Joint M\&S Requirements Group led by the Joint Staff/ J8. Several of the initial JWARS tasks warrant emphasis-

- Tasks 2-3. Prepare high level and detailed designs for JWARS. It is anticipated that JWARS will be object-oriented.

- Task 4. Build a prototype of JWARS.

- Task 7. Demonstrate the federation of JWARS with a mobility/logistics simulation prototype. This activity supports the definition of HLA by DMSO.

The initial schedule for JWARS development is shown in Figure 6. The immediate milestones are completion of the high level design by December 1995 , completion of the prototypes by March 1996, and demonstration of federation of prototypes by June 1996 .

\section{STATUS}

JWARS development began in May 1995 after approval of JAMIP by the DepSecDef. By the time of the 1995 Winter Simulation Conference, the high level design will be nearing completion, and building of prototypes will have begun. Details on these activities will be reported at the conference.

\section{AUTHOR BIOGRAPHIES}

WILLIAM G. LESE, JR. is the Deputy Director (Theater Assessments and Planning) within the Office of the Director (Program Analysis and Evaluation) in the Office of the Secretary of Defense (OSD). He received a B.S. degree in mathematics from California University of Pennsylvania in 1963, and M.S. and Ph.D. degrees in mathematics from the University of Delaware in 1968 and 1972 respectively. $\mathrm{He}$ is the OSD sponsor's representative for the Military Operations Research Society. His primary professional focus is ensuring that DoD has the tools and techniques necessary to analyze issues involving joint operations.

JIM METZGER is the Director of the JWARS Office. $\mathrm{He}$ received a B.S. degree in mathematics from Marquette University in 1964, and M.S. and Ph.D. degrees in mathematics from the University of Michigan in 1965 and 1970 respectively. His professional interests lie in $M \& S$ in general, and constructive simulation of theater-level combat and support in particular. 


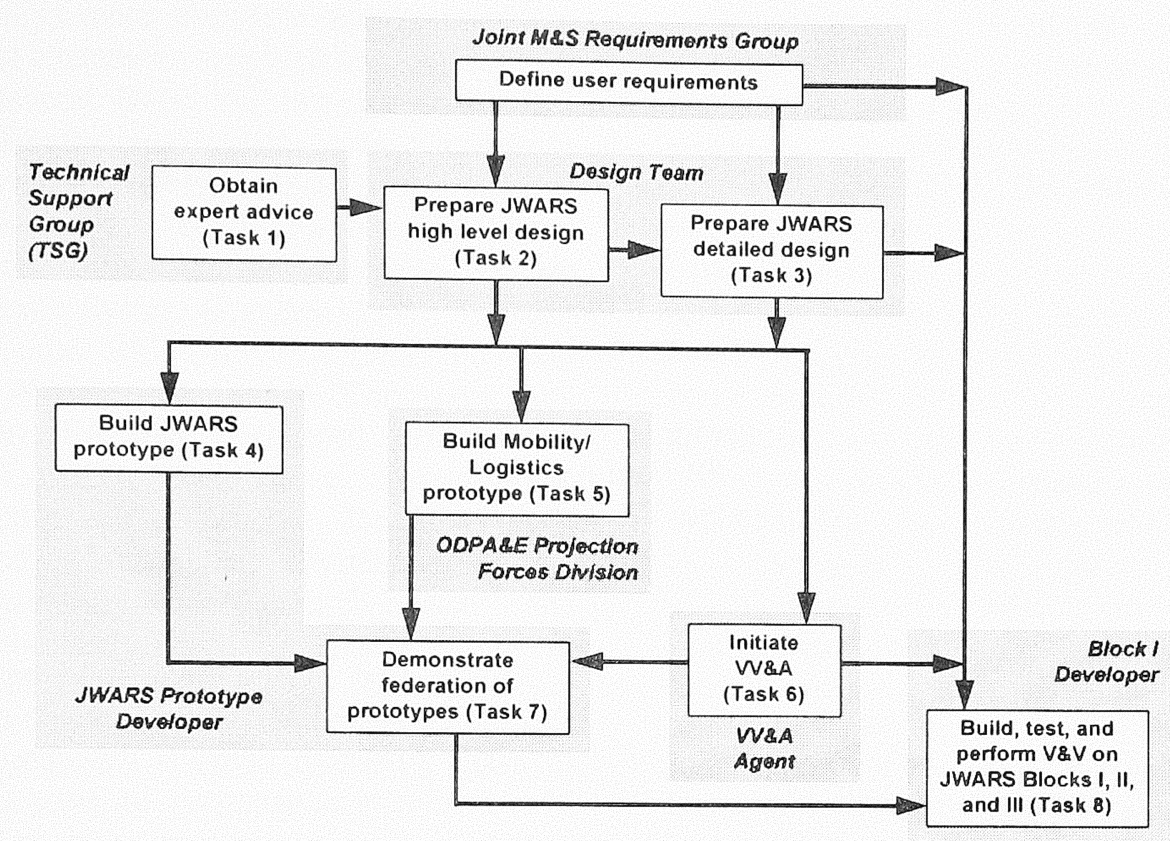

Figure 5: JWARS Approach

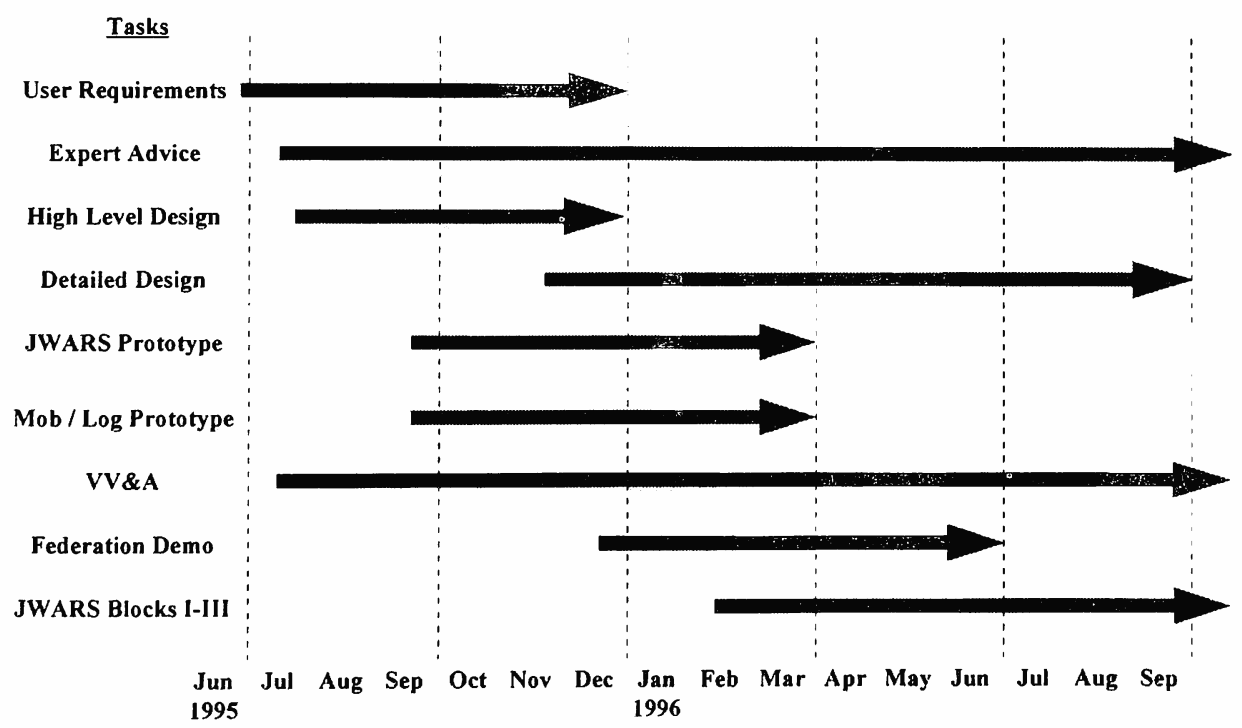

Figure 6: Initial JWARS Schedule 